\title{
Upper Ocean Momentum Balances in the Western Equatorial Pacific on the Intraseasonal Time Scale
}

\author{
Ming Feng ${ }^{\mathrm{a},{ }^{*},}$ Roger Lukas ${ }^{\mathrm{b}}$, Peter Hacker $^{\mathrm{b}}$, Albert Plueddemann ${ }^{\mathrm{c}}$, Robert Weller $^{\mathrm{c}}$ \\ ${ }^{\mathrm{a} C S I R O}$ Division of Marine Research, Floreat, Western Australia, Australia \\ ${ }^{\mathrm{b}}$ School of Ocean and Earth Science and Technology \\ University of Hawaii, Honolulu, Hawaii \\ ${ }^{\mathrm{c}}$ Woods Hole Oceanographic Institution, Woods Hole
}

* Corresponding author. Fax: +61 893336555.

Email address: Ming.Feng@ csiro.au 


\begin{abstract}
Surface Meteorology, upper ocean current, and hydrographic measurements, collected along a repeated survey pattern and from a central mooring in the western equatorial Pacific during late 1992 to early 1993, were used to analyse upper ocean momentum balances on the intraseasonal time scale. Wind stresses derived from meteorological measurements were compared with numerical weather prediction products. Advection terms in the momentum equations were estimated by planar fits to the current and hydrographic data. Pressure gradient terms were derived from planar fits to the dynamic heights calculated from the hydrographic data, referenced by balancing the momentum equation in a selected layer below the mixed layer. Under prevailing westerly winds, westward pressure gradient forcings of $2 \times 10^{-7} \mathrm{~m} \mathrm{~s}^{-2}$ were set up in the western equatorial Pacific, countering the surface wind, while the total advection tended to accelerate the eastward momentum in the surface layer. During both calm wind and westerly wind burst periods, zonal turbulent momentum fluxes estimated from the ocean budgets were comparable with those estimated from microstructure dissipation rate measurements and with zonal wind stresses, so that the zonal momentum could be balanced within error bars. The meridional momentum balances were noisier, which might be due to the fact that the short meridional length scale of the equatorial inertial-gravity waves could contaminate the dynamic signals in the mixed temporal/spatial sampling data, so that the meridional gradient estimates from the planar fits could be biased.
\end{abstract}




\section{Introduction}

The Tropical Ocean Global Atmosphere (TOGA) program conducted its Coupled OceanAtmosphere Response Experiment (COARE) in the western equatorial Pacific including the Intensive Observing Period (IOP) from November 1992 through February 1993 (Webster and Lukas, 1992). The COARE dataset provided a unique opportunity to study the atmospheric Intraseasonal Oscillation (ISO) and its impacts on the evolution of the coupled atmosphere-ocean system in the western Pacific warm pool (Lukas, et al., 1995; Godfrey et al., 1998).

Because of the importance the heat and freshwater fluxes in the air-sea coupling of the western equatorial Pacific, significant efforts were devoted to diagnosing and closing the upper ocean heat and salt balances during the IOP (Weller and Anderson, 1996; Anderson et al., 1996; Cronin and McPhaden, 1997; 1998; Feng et al., 1998a, 2000; Richards and Inall, 2000). The observed westerly wind bursts, related to the ISO, not only caused upper ocean heat loss in the warm pool, but also drove equatorial Kelvin waves which remotely influenced the upper ocean heat budgets in the central and eastern Pacific (Kessler et al., 1996; McPhaden et al., 1998). Thus, validating the surface wind stress during the IOP was also an important aspect of the TOGA COARE research.

During the IOP, surface meteorological measurements were made at a central mooring (deployed by Woods Hole Oceanographic Institution, hereafter called the WHOI mooring), and on board R/V Wecoma and R/V Moana Wave (Fig. 1). The Moana Wave was stationed within $10 \mathrm{~km}$ of the WHOI mooring, and direct estimates of turbulent wind stress using the covariance technique were available from the Moana Wave (Fairall et al., 1996). Comparison of time-averaged data from the Wecoma, Moana Wave, and WHOI mooring showed typical differences of $0.1 \mathrm{~m} \mathrm{~s}^{-1}$ in wind speed and $0.2 \times 10^{-2} \mathrm{~N} \mathrm{~m}^{-2}$ in wind stress (Weller and Anderson, 1996; Godfrey et al., 1998). The disagreements with aircraft measurements were larger. 
Wind stresses were also compared with two numerical weather prediction (NWP) products, one from a reanalysis for the COARE domain by the European Centre for Medium-Range Weather Forecasting (ECMWF; Zhang et al., 2000) and the other from the National Centers for Environmental Prediction (NCEP) reanalysis (Kistler et al., 2001). Comparison to the WHOI mooring showed that the ECMWF stress was consistently lower by $1 \times 10^{-2} \mathrm{Nm}^{-2}$ during the IOP (Weller and Anderson, 1996). The NCEP stress had similar bias. Zhang et al. (2000) applied the COARE bulk flux algorithm (Fairall et al., 1996) to the ECMWF data in an attempt to improve the agreement with the mooring. This "blended" stress product showed a slight improvement that was most noticeable during low winds, reducing the discrepancy by $0.2 \times 10^{-2} \mathrm{Nm}^{-2}$ on average. The reasons for the poor performance of the NWP products was presumed to be their inability to resolve mesoscale processes (e.g. convection) that were important to the development of the local surface wind (Godfrey et al., 1998).

There were limited studies of the momentum balance using the COARE IOP data (Wijesekera and Gregg, 1996; Smyth et al., 1996). Microstructure measurements showed that the wind-induced turbulence occasionally extended below the mixed layer, but had little penetration into the thermocline. These analyses treated the advection and pressure gradient terms as a residual and thus could not provide independent verification of the surface wind stress estimates. Cronin et al. (2000) studied the zonal momentum balance at the equator using multi-mooring data for a two-year period including the IOP. They found that the pressure gradients set up by WWBs could counter the wind stress and drive a subsurface westward jet, which was consistent with modelling results (Zhang and Rothstein, 1998; Richardson et al., 1999). However, they did not attempt to close the momentum budget.

In this study, data collected during the IOP were used to analyse the upper ocean momentum balance. The repeated survey data were used to estimate the momentum advection terms; the same strategy was successfully used in the upper ocean heat and salt budget calculations (Feng et al., 
1998a; 2000). The pressure gradient terms were also estimated from the repeated survey data, a challenge due to the presence of high frequency equatorial inertial-gravity waves. The residual from the upper ocean budget provided independent estimates of the vertical turbulent stresses in the upper ocean and surface wind stresses, to be compared with direct observations.

The organization of the paper is as follows. In section 2, the data and the budget calculation method are introduced. In section 3, we describe the upper-ocean evolution in response to the intraseasonal oscillation during the IOP. In section 4, we present the advection and pressure gradient terms in the momentum balances, and perform the integrated budget calculation. And in section 5, we discuss the errors in the budget calculations. We briefly summarize some ocean dynamics in section 6 .

\section{Data and Methods}

During the IOP, the Wecoma surveyed the upper ocean repeatedly along a butterfly pattern centred at $1.83^{\circ} \mathrm{S}, 156.1^{\circ} \mathrm{E}$ (Fig. 1), with a spatial extent of $130 \mathrm{~km}$ in both zonal and meridional directions, and a repeat period of 1.5 days. Near-continuous Acoustic Doppler Current Profiler (ADCP) and Seasoar/CTD pressure, temperature, and salinity measurements were made along the ship track. The Wecoma observations were collected during three cruises (Huyer et al., 1997; Feng et al., 2000). In the present study, budget calculations are carried out for three time periods during these cruises: November 15 to 30, 1992 (cruise 1), December 20, 1992 to January 7, 1993 (cruise 2), and January 29 to February 13, 1993 (cruise 3). The WHOI mooring was located at $1.75^{\circ} \mathrm{S}$, $156^{\circ} \mathrm{E}$, near the centre of the Wecoma butterfly survey pattern (Fig. 1). Ocean currents from $5 \mathrm{~m}$ down to $260 \mathrm{~m}$ were measured from the mooring using both current meters and a downward looking ADCP. Microstructure measurements were made from the Moana Wave with a multiscale profiler from November 11 to December 3, 1992 during cruise 1 (Wijesekera and Gregg, 1996), and with the CHAMELEON profiler from December 20, 1992 to January 12, 1993 during cruise 2 
(Smyth et al., 1996). The Moana Wave was stationed close to the WHOI mooring. There were no continuous turbulence measurements during cruise 3. Using COARE2.5b bulk flux formulae (Fairall et al., 1996), the air-sea fluxes were estimated from the Wecoma and WHOI mooring surface meteorological measurements (Weller and Anderson, 1996).

The zonal and meridional momentum balance equations are

$$
\begin{aligned}
& \frac{\partial u}{\partial t}+u \frac{\partial u}{\partial x}+v \frac{\partial u}{\partial y}+w \frac{\partial u}{\partial z}-f v+\frac{1}{\rho_{0}} \frac{\partial P}{\partial x}=\frac{1}{\rho_{0}} \frac{\partial \tau^{x}}{\partial z} \\
& \frac{\partial v}{\partial t}+u \frac{\partial v}{\partial x}+v \frac{\partial v}{\partial y}+w \frac{\partial v}{\partial z}+f u+\frac{1}{\rho_{0}} \frac{\partial P}{\partial y}=\frac{1}{\rho_{0}} \frac{\partial \tau^{y}}{\partial z}
\end{aligned}
$$

where $u, v$, and $w$ are the zonal, meridional, and vertical velocities, and positive $x, \mathrm{y}$ and $z$ are eastward, northward and upward, respectively. $f$ is the Coriolis parameter, and $P$ is the pressure disturbance. $\rho_{0}$ is the mean water density. $\tau^{x}$ and $\tau^{y}$ are zonal and meridional Reynolds stresses, and at the sea surface $z=0, \tau^{\mathrm{x}}=\tau^{\mathrm{x} 0}, \tau^{\mathrm{y}}=\tau^{\mathrm{y} 0}$, the surface wind stresses.

The horizontal gradients were calculated from planar fits to the Wecoma data over every two complete butterfly circuits, approximately 3 days (Feng et al., 1998a; 2000). That is, we evaluated $u(x(t), y(t), t)=u_{0}+u_{x} x+u_{y} y+u_{t} t+\varepsilon(x(t), y(t), t)$, where $u=u(x(t), y(t), t)$ are observations at discrete points, $x$ and $y$ are the longitude and latitude relative to the crossover point, $t$ is the time relative to the centre time of the 3 day period, $u_{0}, u_{x}, u_{y}$, and $u_{t}$ are regression coefficients, and $\varepsilon$ is the residual. In this sense, $u_{0}$ represents the mean value of $u$ at the crossover point, $u_{x}$ and $u_{y}$ represent the mean zonal and meridional gradients, and $u_{t}$ is the mean rate of temporal change. Barotropic and coherent baroclinic tides were removed prior to the plane fit (Feng et al., 1998b).

The Wecoma ADCP current data started from 20m, so that assumptions were required for the flow structure from $20 \mathrm{~m}$ to the surface. Four different assumptions were made (Fig. 2): 1) the WHOI mooring shear between 5 and $17 \mathrm{~m}$ was used to estimate the shear in the survey area (WHOI shear); 2) no vertical shear over 0-20m (No shear); 3) the Wecoma hourly current data below 20m were linearly extrapolated to the surface before the plane fit was conducted (Wecoma shear); 4) the 
WHOI mooring 3-day mean velocity was used to replace the Wecoma 3-day mean velocity in the whole water column (WHOI UV). In cases 1, 2 and 4, the velocity divergence in the 0-20m range was kept the same as at $20 \mathrm{~m}$, while in case 3, linear extrapolation of subsurface divergence was used (Fig. 2).

Vertical velocity was calculated from a weighted combination of a divergence method $w=-\int_{z}^{0}(\partial u / \partial x+\partial v / \partial y) d z$ and a density method $w=(\partial \rho / \partial z)^{-1}(-\partial \rho / \partial t-u \partial \rho / \partial x-v \partial \rho / \partial y)$ (Feng et al., 1998a), where the weightings were inversely proportional to the standard errors, estimated by a bootstrap method (Efron and Tibshirani, 1986). The divergence method has less error in the surface mixed layer, while the density method tends to have less error in the upper thermocline (Feng et al., 1998a).

For estimating pressure gradients, the horizontal temperature and salinity gradients were used to fill missing temperature/salinity data near the sea surface, and the dynamic heights were calculated for the individual profiles. Then the plane fit was used to calculate the horizontal gradients of the dynamic heights. The pressure gradients were obtained after shifting the dynamic height gradients to balance the momentum in a reference layer assuming that the average zonal and meridional momentum in the reference layer, $\left[\begin{array}{ll}z_{1} & z_{2}\end{array}\right]$, were balanced over the time interval of each cruise, $\left[t_{1} t_{2}\right]$,

$$
\begin{aligned}
& \left.\frac{\partial P}{\partial x}\right|_{\text {correction }} \quad\left(z_{\text {ref }}\right)=-\frac{\rho_{0}}{\delta t \delta z} \int_{t_{1}}^{t_{2}} \int_{z_{1}}^{z_{2}}\left(\frac{\partial u}{\partial t}+u \frac{\partial u}{\partial x}+v \frac{\partial u}{\partial y}+w \frac{\partial u}{\partial z}-f v\right) d z d t \\
& \left.\frac{\partial P}{\partial y}\right|_{\text {correction }}\left(z_{\text {ref }}\right)=-\frac{\rho_{0}}{\delta t \delta z} \int_{t_{1}}^{t_{2}} \int_{z_{1}}^{z_{2}}\left(\frac{\partial v}{\partial t}+u \frac{\partial v}{\partial x}+v \frac{\partial v}{\partial y}+w \frac{\partial v}{\partial z}+f u\right) d z d t
\end{aligned}
$$

where $\delta t=t_{2}-t_{1}, \delta z=z_{2}-z_{1}$, and $z_{r e f}=\left(z_{1}+z_{2}\right) / 2$. The vertical turbulent mixing terms over the reference layer were neglected, based on the generally low turbulence below the mixed layer depth measured during the IOP (Smyth et al., 1996). Assuming that the horizontal processes are resolved by the survey data, this leaves the pressure gradient terms as the residual of the momentum 
balances in the reference layer. The reference layer is $80 \mathrm{~m}$ thick and the reference depth selections are given in section 4 .

\section{Intraseasonal Oscillation and Upper Ocean Response during IOP}

During the IOP, there were two active ISO periods, characterized by deep convection and heavy rainfall (Fig. 3; Weller and Anderson, 1996). Two WWB events related to the active ISOs occurred in 13 December 1992 to 4 January 1993 and from 28 January through February 1993.

There was one WWB event centred north of the Wecoma survey area in early November 1992, before cruise 1 (not shown). An easterly wind period occurred during 15-25 January 1993, prior to the late January to February 1993 WWB. During the suppressed phase of the ISO, the upper ocean gained heat through the air-sea interface. During the active phase of the ISO, the upper ocean lost heat due to clouds reducing of the incoming solar radiation and to enhanced evaporative cooling, while it gained freshwater from heavy precipitation (Weller and Anderson, 1996; Godfrey et al., 1998).

The three Wecoma cruises covered different phases of the ISOs (Figure 3ab). Cruise 1 was during the suppressed phase, with relatively calm wind, although there was a short episode of westerly wind on November 25. Cruise 2 captured the strong, multi-peak December 1992 WWB, and low wind period in early January. Throughout cruise 3, frequent and short-lived moderate southeastward wind bursts or squalls dominated (Weller and Anderson, 1996).

The measured surface current was dominantly in the zonal direction. Surface eastward jets were generated by the WWBs, and the subsurface westward jets were always present during the first half of the IOP (Fig. 3c). Northward flow was observed in the surface layer following the wind bursts, due to the inertial motions (Fig. 3d). Downward propagating near-inertial gravity waves were observed in this region (Eriksen, 1999), while the surface trapped inertial flow became highly nonlinear due to the $\beta$-effect (Feng et al., 2001). The southern flank of the Equatorial Undercurrent 
(EUC) was observed at the WHOI mooring, and the EUC core intensified and migrated upward from about $190 \mathrm{~m}$ to $160 \mathrm{~m}$ during the IOP (Fig. 3c).

Similar variations were also viewed in the planar fit results of the Wecoma data, using the WHOI shear to fill the 0-20 m gap (Fig. 4). There was one eastward surface pulse during cruise 1, two pulses during cruise 2 , and one pulse during cruise 3 , in response to the WWBs (Fig. 4a). The strongest eastward jet during the IOP $\left(>50 \mathrm{~cm} \mathrm{~s}^{-1}\right)$ was generated by the late December WWB. The northward inertial flow related to this jet was also the strongest, with a subsurface core of more than $30 \mathrm{~cm} \mathrm{~s}^{-1}$ (Fig. 4b).

The cruise-averaged zonal velocities in the surface layer eastward jet, the subsurface westward jet, and the EUC were all strongest during cruise 2 (Fig. 5). A general ascending trend in both the subsurface westward jet and the EUC, as seen in the WHOI current data (Fig. 3c), was also obvious in the cruise averages. The average surface-layer meridional velocity was of the order of $10 \mathrm{~cm} \mathrm{~s}^{-1}$ northward during cruises 2 and 3 due to the inertial motions, while it was southward during cruise 1 (Fig. 5). The average meridional velocities below $80 \mathrm{~m}$ were generally weak, except during cruise 3 . The average vertical velocities were mostly downward in the upper $100 \mathrm{~m}$ due to convergence driven by the dominantly westerly winds, and were upward in the EUC (Fig. 5).

\section{Momentum Balance Results}

\section{a) Advection estimates from Wecoma data}

The zonal gradient of zonal velocity was usually weaker than its meridional gradient (Fig. 6). The meridional gradient was dominantly positive during cruises 1 and 2, when the WWBs were centred north of the butterfly crossover point, and became negative during cruise 3 when the February 1993 WWB was centred south of the crossover point. At the depth of the EUC, positive meridional shear of the zonal velocity dominated as expected. There existed strong meridional shears of zonal current and strong zonal shears of the meridional current between 120 and $200 \mathrm{~m}$ 
during cruise 3 . This was likely due to a subsurface mesoscale eddy identified during this cruise (Mao, 1997). For the meridional velocity, zonal gradients were usually stronger than meridional gradients.

For cruise averages, the total advection tended to accelerate eastward surface flow, while having mixed effects on the meridional flow (Figs. 7 and 8; Tables 1 and 2). Note that negative values denote eastward or northward acceleration because the advection terms are calculated on the left-hand-side of the momentum equations. The cruise-averaged zonal advection tended to accelerate the near-surface zonal velocity to the east in all cruises, though only on the order of $1.0 \times 10^{-7} \mathrm{~m} \mathrm{~s}^{-2}$ (Fig. 7). The mean meridional advection in the upper $80 \mathrm{~m}$ tended to accelerate the eastward current during cruises 1 and 3, while decelerating during cruise 2. There was strong downward transfer of eastward momentum during cruise 2, due to stronger downward vertical velocity and velocity shear (Fig. 7). The vertical advection accelerated the eastward momentum above the EUC core, while it had a decelerating effect below the EUC core, during all cruises. Zonal advection in the surface layer accelerated the northward momentum during cruises 1 and 2 , and decelerated it during cruise 3 (Fig. 8). The meridional advection had significant magnitude during cruise 3 , while the vertical advection of meridional momentum is largely unimportant. The large subsurface horizontal advection during cruise 3 was related to the subsurface mesoscale eddy.

Removing the inertial motions by adding 0-100 m integrated local acceleration and the Coriolis terms, the residual tended to follow surface wind variations on some occasions, but with substantial imbalances (Figs. 9). The Coriolis term used here did not consider the latitudinal changes of Coriolis parameter along the Wecoma track. Efforts to improve this by including the latitudinal variations did not significantly change the results. The imbalances were presumably due to advection and pressure gradient terms. Near the end of cruise 2, advection did account for the imbalance in the zonal momentum (Fig. 9). On other occasions, the advection correction did not significantly improve the imbalance, and even worsened it. The advection terms were only larger 
than the standard errors in the cruise-averaged sense, so that only the cruise-averaged momentum budgets will be presented in the following sections.

\section{b) Pressure gradient estimation}

To avoid cumulative errors in the dynamic height calculations, the pressure gradients were referenced so that momentum was balanced in a selected layer just below the mixed layer. The layers were $80 \mathrm{~m}$ thick and were centred at $80 \mathrm{~m}$ for cruise $1,120 \mathrm{~m}$ for cruise 2, and $100 \mathrm{~m}$ for cruise 3. An example for cruise 2 is shown in Fig. 10, which demonstrates closer comparisons between the corrected geostrophic current and ADCP-derived current in the reference layer. Note that the large differences between the meridional components from ADCP and geostrophic velocities in the upper $80 \mathrm{~m}$ (Fig. 10a) are due to westerly-wind-driven motions. During cruise 3, the selection of $100 \mathrm{~m}$ as the reference layer was necessitated by the strong eddy observed below $120 \mathrm{~m}$ (Fig. 6), which introduced additional errors in the pressure gradient referencing.

During all cruises, the average zonal pressure gradients were weakly positive near the surface (Fig. 11), with magnitude of $2.0 \times 10^{-7} \mathrm{~m} \mathrm{~s}^{-2}$, similar to the two-year average zonal pressure gradient at the equator (Cronin et al., 2000). By adding the pressure gradient with all the other terms on the left hand sides of equations (1) and (2), the residual contained dominantly the vertical divergence of zonal Reynolds stress. All three cruises had positive residuals in the upper $60 \mathrm{~m}$, implying the eastward Reynolds stress due to the wind forcing. Note that the strong pressure signal related to the subsurface mesoscale eddy during cruise 3 was mostly offset by the other terms.

The meridional pressure gradients were generally greater than the zonal pressure gradients, with positive values during cruises 1 and 2, and negative values during cruise 3 in the surface layer (Fig. 12). The sums of the Coriolis term, the local acceleration, and the advection terms are all negative near the surface during the three cruises. Adding the pressure gradient term, the residuals for the meridional momentum are negative in the upper $60 \mathrm{~m}$ in all three cruises, with similar 
magnitudes. This is consistent with the southward wind stress component during cruises 1 and 2 (Fig. 9).

\section{c) Integrated budget calculations}

Integrating the residuals over the upper ocean (from $60 \mathrm{~m}$ for cruise 1 and from $100 \mathrm{~m}$ for cruises 2 and 3, the depths where microstructure measurements indicated low turbulence), we estimated the turbulent Reynolds stress profile and surface wind stress for each cruise (Fig. 13). For the three different 0-20 m vertical shear assumptions in section 2, there were only small differences in the results. Using the WHOI mooring velocity directly could affect the surface wind stress estimates by up to $1.0 \times 10^{-2} \mathrm{~N} \mathrm{~m}^{-2}$.

The integrated residuals of the zonal momentum budgets were comparable to zonal wind stresses from surface measurements in all three cruises. (The WHOI zonal wind stress agreed with the NCEP reanalysis and the blended product to within $0.5 \times 10^{-2} \mathrm{~N} \mathrm{~m}^{-2}$ for the IOP, Table 1). During cruise 2, the zonal wind stress was about $5.0 \times 10^{-2} \mathrm{~N} \mathrm{~m}^{-2}$ eastward from the surface estimates (Table 1). The budget integrations using three different 0-20 m shears (No shear, WHOI shear, and Wecoma shear) all overestimated the surface stress by almost $1.0 \times 10^{-2} \mathrm{~N} \mathrm{~m}^{-2}$, while the budget integration directly using WHOI velocity (WHOI UV) underestimated the surface stress. During cruise 3 , when there was a mean eastward surface zonal wind stress of about $3.0 \times 10^{-2} \mathrm{~N} \mathrm{~m}^{-}$ ${ }^{2}$, the budget integrations using the three different vertical shears all slightly underestimated the wind stress, while the budget using WHOI velocity (WHOI UV) had better closure (Table 1). In summary, the zonal momentum budget was closed to within $1.0 \times 10^{-2} \mathrm{~N} \mathrm{~m}^{-2}$ of the surface wind stress, and the WHOI UV case gave a better closure during cruise 3.

There were larger discrepancies between the WHOI measurements and the reanalysis products for the meridional wind stress, with the latter being about $50 \%$ and $30 \%$ smaller than the former respectively during cruises 2 and 3 (Fig. 13; Table 2). The meridional momentum budget 
closures were less consistent with the surface wind stresses. During cruise 1, the budget results suggested about $-2.0 \times 10^{-2} \mathrm{~N} \mathrm{~m}^{-2}$ meridional wind stress, while the stresses estimated from all measurements and reanalysis products were near zero. The ocean budget using WHOI velocity (WHOI UV) gave a slightly less biased estimate. During cruise 2, the ocean budget estimates were closer to the reanalysis products, other than the measurement estimates. During cruise 3 , the ocean budget estimates from the three different shears were between the WHOI mooring wind stress and the reanalysis products, while the ocean budget based on WHOI mooring velocity was closer to the WHOI mooring wind stress (Fig. 13; Table 2).

In Figure 13, we also compared the Reynolds stress calculated from the upper ocean momentum budgets with those derived from the microstructure measurements during cruises 1 and 2. The Reynolds stresses were expressed as:

$$
\tau^{x}=-\rho_{0} K_{m} \frac{\partial u}{\partial z}, \quad \tau^{y}=-\rho_{0} K_{m} \frac{\partial v}{\partial z}
$$

where the turbulent viscosity was calculated from the microstructure dissipation rate, following Smyth et al. (1996),

$$
K_{m}=\frac{1}{1-R_{f}} \frac{\varepsilon}{S h^{2}}
$$

Here $\varepsilon(z, t)$ is the turbulent kinetic energy dissipation rate from the microstructure measurements (Smyth et al., 1996). Sh is the vertical shear of horizontal velocity and $R_{f}=0.17$, equivalent to a mixing efficiency of approximately 0.2. The mixing efficiency selection was affirmed by largeeddy simulation results (Skyllingstad et al., 1999). In this calculation, we set the minimum $S h^{2}$ to be $1 \times 10^{-6} \mathrm{~s}^{-2}$, which only had minor influence on the result.

There were general agreements between the ocean budget estimation and the microstructure measurements during cruises 1 and 2, except for the meridional component in cruise 1 (Fig. 13). Assuming Reynolds stress from 20-50 m could be linearly extrapolated to the sea surface to obtain the surface wind stress, the zonal Reynolds stresses from the microstructure measurements are 
generally consistent with the surface stress estimates (Fig. 13; Smyth et al., 1996). During cruise 2, the microstructure data suggested a slightly more southward wind stress than the ocean budget, more consistent with the WHOI mooring surface wind stress estimate. For cruise 3, a similar comparison was not attempted due to insufficient microstructure measurements.

In summary, during both the calm wind and westerly wind burst periods, zonal turbulent momentum fluxes estimated from the ocean budgets were comparable with those estimated from microstructure dissipation rate measurements and with zonal wind stresses, so that the zonal momentum could be balanced within the error bars discussed in the next section.

\section{Error Estimates}

Discrepancies between the observed wind stresses and the ocean budget estimates could be due to errors in surface wind stress calculation, errors in the ocean budget estimation, and the incompatibilities between the two in terms of spatial scale.

Some of the differences among the meridional wind stress estimates might be due to spatial variation of the wind field. The Wecoma wind stress numbers shown in Tables 1 and 2 were simple averages of the hourly wind stresses over the cruise time periods. The absolute differences between the WHOI and Wecoma stresses were $0.3 \times 10^{-2} \mathrm{~N} \mathrm{~m}^{-2}$ on average, and could be as large as $0.5 \times 10^{-2}$ $\mathrm{N} \mathrm{m}^{-2}$. These differences were used as indicators of surface stress errors in Tables 1 and 2 . The Wecoma wind stresses contained both temporal and spatial information and their gradients were calculated using the same methods as the subsurface data (not shown). Considering the 0.1 degree longitude and latitude differences between the WHOI mooring and the Wecoma crossover point, the horizontal gradients can only account for less than $0.2 \times 10^{-2} \mathrm{~N} \mathrm{~m}^{-2}$ of the difference.

Bootstrap analysis (Efron and Tibshirani, 1986) was used to estimate the errors of the planar

fit, and then in the advective terms (Feng et al., 1998a). Assuming that the errors in the three 
advective terms were independent, and with a decoupling time scale of three days, the standard errors of momentum advection were up to $0.5 \times 10^{-2} \mathrm{~N} \mathrm{~m}^{-2}$ (Tables 1 and 2).

Projecting the planar fit of Wecoma velocity to the WHOI mooring site, the differences from the WHOI measurements provided an assessment of errors from the Coriolis term. Note that when estimating the Coriolis term, a $0.02 \mathrm{~m} \mathrm{~s}^{-1}$ bias in mean velocity would cause a $1.0 \times 10^{-2} \mathrm{~N} \mathrm{~m}^{-2}$ error in estimating stress when integrated over $100 \mathrm{~m}$ at the latitude of the crossover point. The largest error was $0.7 \times 10^{-2} \mathrm{~N} \mathrm{~m}^{-2}$ for cruise 3 (Tables 1 and 2). Errors from the local acceleration term were evaluated with the mean velocity errors at the beginning and the end of each cruise. The errors were up to $0.4 \times 10^{-2} \mathrm{~N} \mathrm{~m}^{-2}$ in the zonal component for cruise 2 and in the meridional components for cruises 1 and 3 (Tables 1 and 2).

Errors of the pressure gradient were estimated to have two sources: one was the total error of all the terms in equations (3) and (4) within the reference layer, and the other was the error in estimating the integrated dynamic height gradients. The two sources of errors have comparable amplitudes, and were usually larger than the other error terms in the momentum balances (Tables 1 and 2). Except for the meridional components of cruises 1 and 2, the momentum budget was balanced in the sense that the discrepancies between the wind stress estimates from the ocean budget and WHOI mooring were within the standard error bars.

Thus, the pressure gradient was the most error-prone term to estimate in order to balance the upper ocean momentum budgets. The cancellation between the local acceleration and the Coriolis acceleration could also cause a problem. Still, the misfits for the meridional momentum balance tended to be larger than the total standard error bar, which implied that the mixed temporal-spatial sampling might alias the dynamic signals in the meridional momentum budget due to short meridional length scale in the equatorial region. The planar fits could produce biased estimates of the meridional gradients in the thermocline of the near-equatorial region. 


\section{Summary}

In this section, we briefly summarize some ocean dynamics derived from the analysis:

- $\quad$ To quantify the momentum balance at low latitudes on intraseasonal time scales, inertial motion induced advection has important contributions and needs to be resolved.

- Under prevailing westerly winds during the IOP, a westward pressure gradient forcing of $2 \times 10^{-7} \mathrm{~m} \mathrm{~s}^{-2}$ was set up in the western equatorial Pacific, to counter the surface wind, while total advection tended to accelerate the eastward momentum in the surface layer at the centre of the survey domain.

- The zonal momentum balance was closed, in that momentum fluxes estimated from the ocean budgets agreed with those from microstructure dissipation rate measurements and zonal wind stresses within observational error. The meridional momentum balances were not as consistent. We believe that this result is a signal versus noise issue: the meridional gradients estimated from the planar fits are more subjective to the "noise" from the inertial-gravity waves that are incompletely resolved by our shipboard sampling.

- Although the prevailing westerly wind drove a surface layer downwelling, there was a general upwelling tendency in the EUC, likely due to equatorial wave propagations. Thus, upper ocean response to remote forcing may also be important in the local dynamic balance.

\section{Acknowledgments}

MF acknowledges the support of Strategic Research Fund for Marine Environment. RL and PH were supported by NSF grant OCE-9525986. RW and AP were supported by NSF Grants OCE9110559 and OCE-9110554, respectively. The authors appreciate the valuable discussions with Eric Firing and excellent computing support provided by Sharon DeCarlo. We would also thank Michael Bacon, the Editor of DSR- I , and two anonymous reviewers for helpful comments. This is SOEST publication 6486, and WHOI publication 11258. 


\section{References}

Anderson, S. P., Weller, R. A., Lukas, R., 1996. Surface buoyancy forcing and the mixed layer of the western Pacific warm pool: Observations and 1-d model results. Journal of Climate 9, 3056-3085.

Cronin, M. F., McPhaden, M. J., 1997. The upper ocean heat balance in the western equatorial Pacific warm pool during September-December 1992. Journal of Geophysical Research 102, 8533-8553.

Cronin, M. F., McPhaden, M. J., 1998. Upper ocean salinity balance in the western equatorial Pacific. Journal of Geophysical Research 103, 27,567-27,587.

Cronin, M. F., McPhaden, M. J., Weisberg, R. H., 2000. Wind-forced reversing jets in the western equatorial Pacific. Journal of Physical Oceanography 30, 657-676.

Efron, B., Tibshirani, R. J., 1986. Bootstrap methods for standard errors, confidence intervals and other measures of statistical accuracy. Statistical Science 1, 54-77.

Eriksen, C. C., 1999. Observations of low-latitude, near-inertial gravity waves forced by westerly wind bursts. Dynamics of Oceanic internal gravity waves II. Proceedings Hawaiian Winter Workshop, 173-180, University of Hawaii at Manoa, January 18-22, 1999.

Fairall, C., Bradley, E. F., Rogers, D. P., Edson, J. B., Young, G.S., 1996. The TOGA COARE bulk flux algorithm. Journal of Geophysical Research 101, 3747-3764.

Feng, M., Hacker, P., Lukas R., 1998a. Upper Ocean Heat and Salt Balances in Response to a Westerly Wind Burst in the Western Equatorial Pacific during TOGA COARE. Journal of Geophysical Research 103, 10,289-10,311.

Feng, M., Merrifield, M., Pinkel, R., Hacker P., Pluddemann, A., Firing, E., Lukas, R., Eriksen, C., 1998b. Semidiurnal tides observed in the western equatorial Pacific during TOGA COARE. Journal of Geophysical Research 103, 10,253-10,272.

Feng, M., Lukas, R., Hacker, P., Weller, R., Anderson, S. P., 2000. Upper ocean heat and salt balances in the western equatorial Pacific in response to the intraseasonal oscillation during TOGA COARE. Journal of Climate 13, 2409-2427.

Feng, M., Lukas, R., Hacker, P., 2001. Spin-up of a sub-mesoscale eddy in the TOGA COARE Intensive Flux Array during the spin-down of an intense eastward jet. Journal of Physical Oceanography 31, 711-724. 
Godfrey, J. S., Houze, R. A. Jr., Johnson, R. H., Lukas, R., Redelsperger, J.-L., Sumi, A., Weller, R., 1998. COARE. Journal of Geophysical Research 103, 14,395-14,450.

Huyer, A., Kosro, P. M., Lukas, R., Hacker, P., 1997. Upper-ocean thermohaline fields near $2^{\circ}$ S, $156^{\circ} \mathrm{E}$ during TOGA-COARE, November 1992 to February 1993. Journal of Geophysical Research 102, 12,749-784.

Lukas, R., Webster, P., Ji, M., Leetmaa, A., 1995. The large-scale context for the TOGA COARE. Meteorology and Atmospheric Physics 56, 3-16.

Mao, M., 1997. Analysis of three dimensional current structures using ship-mounted ADCP. Masters thesis, University of Hawaii, 105 pp.

McPhaden, M. J., et al., 1998. The Tropical Ocean-Global Atmosphere observing system: A decade of progress. Journal of Geophysical Research 14,169-14,240.

Kessler, W. S., McPhaden, M. J., Weickmann, K. M., 1996. Forcing of intraseasonal Kelvin waves in the equatorial Pacific. Journal of Geophysical Research 100, 10,613-10,631.

Kistler, R. et al., 2001. The NCEP-NCAR 50-year reanalysis: monthly means CD-ROM and documentation. Bulletin of the American Meteorological Society 82, 247-267.

Richards, K. J., Inall, M. E., 2000. The upper ocean heat content in the western equatorial Pacific: processes controlling its change during the TOGA COARE. Journal of Geophysical Research $105,19,575-19,590$.

Richardson, R., Ginis, I., Rothstein, L., 1999. A numerical investigation of the local ocean response to westerly wind burst forcing in the western equatorial Pacific. Journal of Physical Oceanography 29, 1334-1352.

Skyllingstad, E., Smyth, W., Moum, J., Wijesekera, H., 1999. Upper-ocean turbulence during a westerly wind burst: a comparison of large-eddy simulation results and microstructure measurements. Journal of Physical Oceanography 29, 5-28.

Smyth, W. D., Hebert, D, Moum, J. N., 1996. Local ocean response to a multiphase westerly windburst, Part 1: dynamic response. Journal of Geophysical Research 101, 22,495-22,512.

Webster, P.J., Lukas, R., 1992. TOGA COARE: The coupled ocean-atmosphere response experiment. Bulletin of American Meteorological Society 73, 1377-1415.

Weller, R. A., Anderson, S. P., 1996. Surface meteorology and air-sea fluxes in the western equatorial Pacific warm pool during the TOGA Coupled Ocean-Atmosphere Response Experiment. Journal of Climate 9, 1959-1990.

Wijesekera, H. W., Gregg, M. C., 1996. Mixing in the western equatorial Pacific during the first leg of TOGA-COARE. Journal of Geophysical Research 101, 977-998. 
Zhang, Q., Rothstein, L., 1998. Modeling the oceanic response to westerly wind bursts in the western equatorial Pacific. Journal of Physical Oceanography 28, 2227--2249.

Zhang, S., Plueddemann, A. J., Anderson, S. P., Weller, R. A., 2000. Surface fluxes and their influence on sea surface temperature in the western equatorial Pacific during the Coupled Ocean-Atmosphere Response Experiment. Journal of Geophysical Research 105, 6341-6357. 


\section{Figure Captions:}

Fig. 1: R/V Wecoma survey track during the IOP. The position of the WHOI mooring is indicated (the R/V Moana Wave was stationed within $10 \mathrm{~km}$ of the WHOI mooring).

Fig. 2: Sketch of 0-20 m current velocity (a) and velocity divergence (b) assumptions: 1) WHOI shear; 2) Constant; 3) Wecoma shear; and 4) WHOI UV.

Fig. 3: Zonal (a) and meridional (b) wind stress calculated from surface data of the WHOI mooring during the IOP, and zonal (c) and meridional (d) current velocity from the WHOI mooring. The current data are 3-day averaged and the unit for the velocity is $\mathrm{cm} \mathrm{s}^{-1}$. The shadings in (a) and (b) denote the time periods of the Wecoma cruises. Positive wind speeds and current velocities are eastward and northward respectively.

Fig. 4: Mean zonal (a) and meridional (b) current velocity from the plane fit of the Wecoma data. The unit is $\mathrm{cm} \mathrm{s}^{-1}$. Positive velocities are eastward and northward respectively.

Fig. 5: Cruise-averaging zonal (a), meridional (b), and vertical (c) velocities. Positive velocities are eastward, northward, and upward, respectively.

Fig. 6: Velocity gradients from plane fit. The units are $10^{-6} \mathrm{~s}^{-1}$.

Fig. 7: Cruise-averaged advection terms of zonal momentum balance. Negative values accelerate eastward momentum as in equation (1).

Fig. 8: Cruise-averaged advection terms of meridional momentum balance. Negative values accelerate northward momentum as in equation (2).

Fig. 9: 0-100 m integrated local acceleration term plus Coriolis term in the zonal (a) and meridional (b) momentum balance equations from the Wecoma data, and their comparison with the WHOI surface wind stresses. Shadings are same as in Fig. 3.

Fig. 10: Comparison of cruise-averaged ADCP meridional (a) and zonal (b) velocities and geostrophic estimates with and without corrections (see text) for cruise 2. 
Fig. 11: Cruise-averaged zonal pressure gradient term (a), the total advection plus Coriolis term (b), and their sum (c) in the zonal momentum equation (1).

Fig. 12: Cruise-averaging meridional pressure gradient term (a), the total advection plus Coriolis term (b), and their sum (c) in the meridional momentum equation (2).

Fig. 13: Comparison between the Reynolds stresses calculated from the upper ocean momentum budget and microstructure measurements. (a) and (b) are for cruise 1, (c) and (d) for cruise 2, and (e) and (f) for cruise 3. Also shown are the cruise-averaged wind stresses from the WHOI mooring and from NCEP and blended ECMWF reanalyses. The standard errors from the ocean budgets are indicated at the WHOI wind stresses. 
Table 1

Integrated surface layer zonal momentum balance using WHOI mooring surface shear to fill the 0$20 \mathrm{~m}$ gap in the Wecoma current velocity (WHOI shear).

\begin{tabular}{|l|c|c|c|}
\hline & Cruise 1 & Cruise 2 & Cruise 3 \\
\hline Unit: $10^{-2} \mathrm{Nm}^{-2}$ & Nov.15-30,1992 & Dec.20,1992-Jan.7,1993 & Jan.29-Feb.13, 1993 \\
\hline Temporal Change & $1.0(0.1)$ & $0.6(0.4)$ & $0.2(0.1)$ \\
\hline Total Advection & $-0.6(0.2)$ & $-1.2(0.5)$ & $-1.5(0.3)$ \\
\hline Zonal & -0.1 & -0.6 & -0.3 \\
\hline Meridional & -0.3 & 0.8 & -1.2 \\
\hline Vertical & -0.2 & -1.4 & $3.3(1.2)$ \\
\hline Pressure Gradient & $1.2(0.4)$ & $1.9(1.1)$ & $0.5(0.7)$ \\
\hline Coriolis Term & $-1.0(0.3)$ & $4.6(0.5)$ & $2.5(1.5)$ \\
\hline Sum & $0.6(0.6)$ & $5.9(1.4)$ & $3.3(0.5)$ \\
\hline WHOI Mooring Stress & $0.7(0.1)$ & $5.2(0.3)$ & 3.8 \\
\hline Wecoma stress & 0.6 & 5.5 & 3.0 \\
\hline NCEP stress & 0.7 & 4.7 & \\
\hline Blended stress & & & \\
\hline Note: Sign convecton & & & \\
\hline & & & \\
\hline
\end{tabular}

Note: Sign convection is as in equations (1), and error estimates are indicated in parentheses. 
Table 2

Integrated surface layer meridional momentum balance using WHOI mooring surface shear to fill the 0-20 m gap in the Wecoma current velocity (WHOI shear).

\begin{tabular}{|l|c|c|c|}
\hline & Cruise 1 & Cruise 2 & Cruise 3 \\
\hline Unit: 10-2 N m-2 & Nov.15-30,1992 & Dec.20,1992-Jan.7,1993 & Jan.29-Feb.13,1993 \\
\hline Temporal Change & $0.4(0.4)$ & $0.9(0.1)$ & $1.4(0.4)$ \\
\hline Total Advection & $-1.9(0.2)$ & $-0.8(0.4)$ & $1.1(0.3)$ \\
\hline Zonal & -1.7 & -1.6 & 0.5 \\
\hline Meridional & -0.2 & 0.4 & 0.6 \\
\hline Vertical & 0.0 & 0.4 & $-2.5(0.8)$ \\
\hline Pressure Gradient & $3.1(0.5)$ & $4.2(1.0)$ & $-2.6(0.2)$ \\
\hline Coriolis Term & $-4.0(0.1)$ & $-6.5(0.5)$ & $-2.6(1.0)$ \\
\hline Sum & $-2.4(0.7)$ & $-2.2(1.2)$ & $-3.0(0.2)$ \\
\hline WHOI Mooring Stress & $0.1(0.1)$ & $-3.9(0.3)$ & -2.8 \\
\hline Wecoma stress & -0.1 & -3.6 & -1.9 \\
\hline NCEP stress & -0.3 & -2.0 & -2.0 \\
\hline Blended stress & -0.1 & & \\
\hline
\end{tabular}

Note: Sign convection is as in equations (2), and error estimates are indicated in parentheses. 